\title{
Article \\ Methylammonium Lead Tri-Iodide Perovskite Solar Cells with Varying Equimolar Concentrations of Perovskite Precursors
}

\author{
Mritunjaya Parashar ${ }^{1}$ and Anupama B. Kaul ${ }^{1,2, * \mathbb{D}}$ \\ 1 Department of Electrical Engineering, PACCAR Technology Institute, University of North Texas, \\ Denton, TX 76207, USA; mritunjayaparashar@my.unt.edu \\ 2 Department of Materials Science and Engineering, University of North Texas, Denton, TX 76207, USA \\ * Correspondence: anupama.kaul@unt.edu
}

Citation: Parashar, M.; Kaul, A.B. Methylammonium Lead Tri-Iodide Perovskite Solar Cells with Varying Equimolar Concentrations of Perovskite Precursors. Appl. Sci. 2021, 11, 11689. https://doi.org/10.3390/ app112411689

Academic Editor: Alejandro Pérez-Rodróhiez

Received: 19 November 2021 Accepted: 7 December 2021 Published: 9 December 2021

Publisher's Note: MDPI stays neutra with regard to jurisdictional claims in published maps and institutional affiliations.

Copyright: (c) 2021 by the authors. Licensee MDPI, Basel, Switzerland. This article is an open access article distributed under the terms and conditions of the Creative Commons Attribution (CC BY) license (https:/ / creativecommons.org/licenses/by/ $4.0 /)$.

\begin{abstract}
During recent years, power conversion efficiencies (PCEs) of organic-inorganic halide perovskite solar cells (PSCs) have shown remarkable progress. The emergence of various thin film deposition processes to produce perovskite films, notably using solution processing techniques, can be credited in part for this achievement. The engineering of chemical precursors using solution processing routes is a powerful approach for enabling low-cost and scalable solar fabrication processes. In the present study, we have conducted a systematic study to tune the equimolar precursor ratio of the organic halide (methylammonium iodide; $\mathrm{MAI}$ ) and metal halide (lead iodide; $\mathrm{PbI}_{2}$ ) in a fixed solvent mixture of $N, N$-dimethylformamide (DMF):dimethylsulfoxide (DMSO). The surface morphology, optical characteristics, and crystallinity of the films produced with these four distinct solutions were investigated, and our analysis shows that the MAI:PbI 2 (1.5:1.5) film is optimal under the current conditions. The PSCs fabricated from the (1.5:1.5) formulation were then integrated into the n-i-p solar cell architecture on fluorine-doped tin oxide (FTO) substrates, which exhibited a PCE of $\sim 14.56 \%$. Stability testing on this PSC device without encapsulation at $29{ }^{\circ} \mathrm{C}$ (ambient temperature) and $60 \%$ relative humidity $(\mathrm{RH})$ under one-sun illumination while keeping the device at its maximum power point showed the device retained $\sim 60 \%$ of initial PCE value after $10 \mathrm{~h}$ of continuous operation. Moreover, the recombination analysis between all four formulations showed that the bimolecular recombination and trap-assisted recombination appeared to be suppressed in the more optimal (1.5:1.5) PSC device when compared to the other formulations used in the n-i-p PSC architecture.
\end{abstract}

Keywords: perovskite solar cells; equimolar concentration; solution processing; organic halide; metal halide; n-i-p

\section{Introduction}

The past decade has witnessed increasing interest in novel materials such as graphene and its hybrids [1,2], transition metal dichalcogenides (TMDCs) [3], black phosphorus [4], and organic-inorganic metal halide perovskites as promising optoelectronic materials for solid-state photovoltaics [5], light-emitting diodes (LEDs) [6], lasers [7], photodetectors [8-10], and photocatalysts [11]. Perovskite materials exhibit many remarkable optoelectronic properties such as broad bandgap tunability [12,13], high absorption coefficients [5], ambipolar charge transport properties [14], long charge carrier diffusion lengths $(>1 \mu \mathrm{m})$ [15], high charge carrier mobilities [16], low non-radiative recombination rates $[17,18]$, and high emission color purity [19]. Aside from that, ionic conductivity in perovskites arises from ion/defect migration, which has revealed a fascinating feature toward switchable resistance depending on the history of the last applied bias. This ability to reliably regulate ion migration and hysteresis has aided in the development of memristors devices (memory + resistor) based on the unique structural properties provided by perovskites [20]. These remarkable properties make perovskites ideal candidates for their use as light-harvesting materials in solar cells and various other devices. 
Perovskite structures have the stoichiometry of $\mathrm{ABX}_{3}$, where $A=$ a large organic/inorganic cation (e.g., $\mathrm{CH}_{3} \mathrm{NH}_{3}{ }^{+}, \mathrm{Cs}^{+}$), $B=$ an inorganic metal cation (e.g., $\mathrm{Pb}^{2+}, \mathrm{Sn}^{2+}$ ), and $X=\mathrm{a}$ halide anion (e.g., $\mathrm{Cl}^{-}, \mathrm{Br}^{-}, \mathrm{I}^{-}$). The formability of the perovskite structure is determined by the geometrical tolerance factor $t$, defined as $t=\frac{\left(r_{A}+r_{X}\right)}{\sqrt{2}\left(r_{B}+r_{X}\right)}$, where $r_{A}, r_{B}$, and $r_{X}$ are the effective ionic radii of the $A, B$, and $X$ ions [21]. The ideal perovskite structure is formed when $t=1$, but a feasible range of values for the formability of alkali metal halide perovskites is $0.813<t<1.107$ [22].

While the organic halide (e.g., methylammonium iodide (MAI)) component of the perovskite dissolves readily in virtually all polar solvents, finding a solvent to dissolve the metal halide (e.g., lead iodide $\left(\mathrm{PbI}_{2}\right)$ ) component is more difficult. Some of the widely used solvents include $N, N$-dimethylformamide (DMF) and dimethylsulfoxide (DMSO), and the solubility limit of $\mathrm{PbI}_{2}$ has been experimentally determined to be $\sim 450 \mathrm{mg} / \mathrm{mL}$ and $\sim 600 \mathrm{mg} / \mathrm{mL}$ in DMF and DMSO, respectively, which is sufficient to form an adequately thick perovskite film [23,24]. Over the years, several distinct variants of solution-processing by spin coating of perovskite materials have been studied. Such approaches have the common goal to produce perovskite films with dense and homogeneous morphology and large grain size and to achieve optimal crystallinity to yield an effective photoabsorber layer within the photovoltaic solar cell stack. The so-called one-step, two-step, and solvent engineering procedures are the most popular (Figure 1). Using the one-step method, 3D perovskite (e.g., $\mathrm{MAPbI}_{3}$ ) can be readily formed by spin coating the mixture of perovskite precursors (e.g., MAI and $\mathrm{PbI}_{2}$ ) in some polar aprotic solvents, such as $N, N$-dimethylacetamide (DMAc) and DMF. After spin coating, films can be thermally treated at mild temperatures to form the desired perovskite phase [25]. While this method is straightforward and remains widely used for some perovskite compositions [26,27], the perovskite precursors may undergo chemical reactions in the solution that affect the final film structure and composition, with a concomitant impact on the solar cell performance [28]. The two-step method, in which one of the precursors is deposited first, followed by the deposition of a second precursor and thermal annealing, was popular in the early days of perovskite research [29]. Most commonly, the first precursor (e.g., $\left.\mathrm{PbI}_{2}\right)$ is deposited by spin coating, while the second one (e.g., MAI) can be deposited by dipping the sample into a solution [30] or by spin coating on top of the first layer [31]. For a time, devices fabricated using the two-step method performed better than those made using the one-step approach [32], but the situation drastically changed with the advent of the solvent engineering approach [33], which remains the most commonly used method to date.

The solvent engineering method is a variation of the one-step approach, in which all perovskite precursors are deposited in a single step, followed by the application of an antisolvent, which causes the rapid crystallization of the perovskite layer [34]. This method provides the ease of the one-step method and, at the same time, results in better film morphology, similar to that observed for the two-step method. The use of a suitable amount of DMSO (Lewis base) in combination with DMF can form the Lewis acid-base adduct with $\mathrm{PbI}_{2}$ (Lewis acid), which results in the formation of a dense perovskite layer via the MAI$\mathrm{PbI}_{2}$-DMSO intermediate phase. The antisolvent treatment enables the elimination of the host solvent(s) and initiates crystallization of the perovskite film during this intermediate phase, which helps regulate crystal development and morphology of the film. However, the use of an excessive amount of DMSO may lead to pinholes in the perovskite film, and thus, a small volume of DMSO is usually preferred with DMF; here, we used DMF:DMSO $(4: 1)[33,35]$. The rate at which the antisolvent is applied is crucial and one of the decisive steps to determine film quality; thus, an appropriate rate of antisolvent dropping should be optimized for different antisolvents [36]. The convenience and simplicity of solutionprocessed perovskite layers by spin coating, which can be conducted in practically any laboratory without the need of expensive and sophisticated vacuum apparatus, is one of the primary advantages of this method. Another important benefit is the ability to introduce additives to the perovskite precursor solution, which has proven to have a beneficial impact on the final perovskite structure [37]. Therefore, an organized study to optimize 
varying equimolar concentrations during the spin coating of perovskite precursors is highly beneficial in making $\mathrm{MAPbI}_{3}$ PSCs since these are often still used as a benchmark to compare with the growing family of other perovskite-based photoabsorbers for PSCs.

(a)

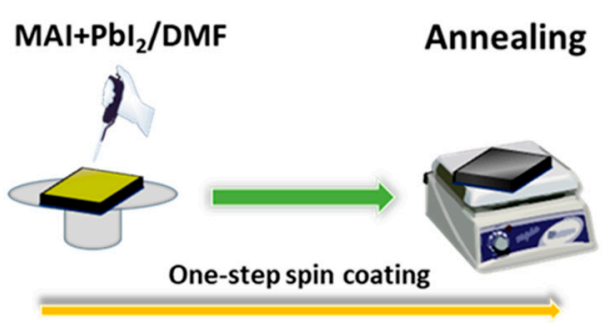

(b)

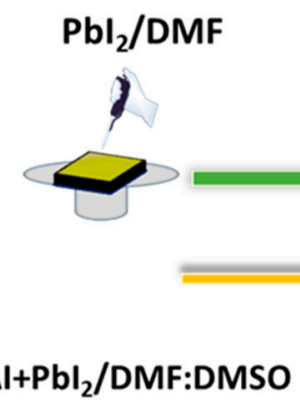

Antisolvent dripping

Annealing

MAI/IPA

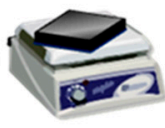

Two-step spin coating

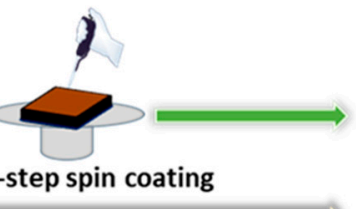

Annealing

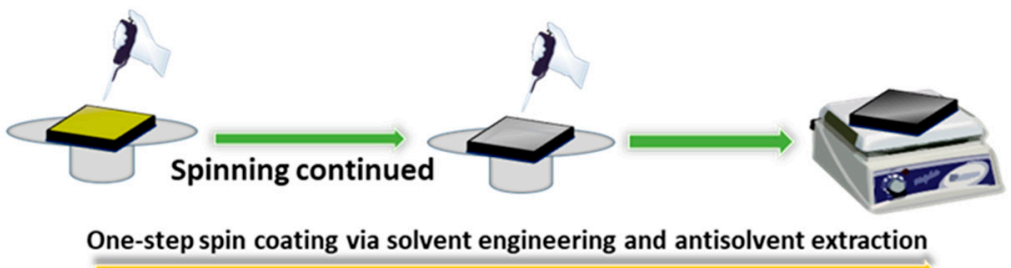

Figure 1. Illustrated are the (a) one-step spin coating, (b) two-step spin coating, and (c) one-step spin coating via solvent engineering and antisolvent extraction methods. In our work, we have used the one-step coating and solvent engineering and antisolvent extraction approach to form our photoabsorber layers.

In the present report, we have conducted a systematic study in tuning the equimolar precursor ratio of the organic halide $(\mathrm{MAI}=1 \mathrm{M}, 1.2 \mathrm{M}, 1.5 \mathrm{M}, 1.6 \mathrm{M})$ and metal halide (lead iodide: $\mathrm{PbI}_{2}=1 \mathrm{M}, 1.2 \mathrm{M}, 1.5 \mathrm{M}, 1.6 \mathrm{M}$ ) in a fixed solvent mixture of DMF:DMSO. Hereafter, the fabricated films and perovskite solar cells (PSCs) with these four different concentrations will be denoted as (1.0:1.0), (1.2:1.2), (1.5:1.5) and (1.6:1.6) in this study. These films were studied and discussed on the basis of their surface morphology, optical properties and crystallinity. Additionally, the n-i-p PSCs fabricated from all four formulations were analyzed for recombination losses and operational stability study, which we also discuss here.

\section{Materials and Methods}

\subsection{Materials}

Lead (II) iodide $\left(\mathrm{PbI}_{2}, 99.99 \%\right)$ was purchased from TCI America, while DMF, DMSO, anhydrous ethanol, toluene, chlorobenzene, acetonitrile, 4-tert-butylpyridine (TBP), titanium diisopropoxide bis(acetylacetonate), and bis(trifluoromethane)sulfonimide lithium salt (Li-TFSI) were purchased from Sigma-Aldrich, St. Louis, MO, USA. The methyl ammonium iodide (MAI, 99.9\%) and tris(2-(1H-pyrazol-1-yl)-4-tert-butylpyridine)cobalt(III) tris-(bis(trifluoromethyl sulfonyl)imide) (FK209) were also purchased from Sigma-Aldrich, St. Louis, MO, USA. Finally, the $2,2^{\prime}, 7,7^{\prime}$-tetrakis-( $N, N$-di-p-methoxyphenylamine)-9, $9^{\prime}$ - 
spirobifluorene (Spiro-OMeTAD) was obtained from Lumtec, Taiwan. All chemicals were used as received.

\subsection{Morphology Characterization}

Field-emission scanning electron microscopy (FE-SEM) was performed using an FEIQuanta environmental SEM. One-dimensional X-ray diffraction (1D-XRD) measurements were conducted using a Rigaku Ultima III X-ray diffractometer.

\subsection{Optical Characterization}

Ultraviolet-visible (UV-vis) optical absorption spectroscopy of the synthesized films was conducted using the Agilent CARY 5000 spectrophotometer. The steady-state photoluminescence (PL) spectra were measured using a LabRAM HR Evolution spectrometer from HORIBA Scientific, equipped with a $\sim 532 \mathrm{~nm}$ laser source for optical excitation.

\subsection{Device Fabrication}

For the PSC device fabrication, first, pre-etched fluorine-doped tin oxide (FTO) coated glass substrates were cleaned rigorously using soapy water, deionized water (DI), ethanol and isopropanol (IPA) for 20 min each under sonication. After cleaning, the substrates were $\mathrm{N}_{2}$ blow-dried to remove the residual solvents from the substrates and then thermally treated in a convection oven at $70{ }^{\circ} \mathrm{C}$ for $30 \mathrm{~min}$. Cleaned substrates were further treated in a UV-ozone plasma for $20 \mathrm{~min}$ before starting the thin film deposition of the solar cell stacking layers. For the fabrication of the n-i-p structure, the cleaned FTO substrates were spin coated with a $0.15 \mathrm{M}$ solution of titanium diisopropoxide bis(acetylacetonate) in ethanol at $3000 \mathrm{rpm}$ for $20 \mathrm{~s}$ to form a compact titanium dioxide $\left(\mathrm{c}-\mathrm{TiO}_{2}\right)$ electron transport layer (ETL) and subsequently annealed at $510{ }^{\circ} \mathrm{C}$ for $30 \mathrm{~min}$. For the perovskite absorber layer, a perovskite precursor solution was prepared with an equimolar precursor ratio of the organic halide $(\mathrm{MAI}=1 \mathrm{M}, 1.2 \mathrm{M}, 1.5 \mathrm{M}, 1.6 \mathrm{M})$ and the metal halide $\left(\mathrm{PbI}_{2}=1 \mathrm{M}, 1.2 \mathrm{M}\right.$, $1.5 \mathrm{M}, 1.6 \mathrm{M}$ ) in a fixed solvent formulation of DMF:DMSO (4:1); all four solutions were stirred at $65{ }^{\circ} \mathrm{C}$ overnight. The perovskite films were then deposited by spin coating these 4 precursor solutions on top of the $\mathrm{c}^{-\mathrm{TiO}_{2}}$ layer via a spin coating program comprising of $8 \mathrm{~s}$ at $1000 \mathrm{rpm}$, with a subsequent ramp to $5100 \mathrm{rpm}$ for $15 \mathrm{~s}$. An amount of $0.1 \mathrm{~mL}$ of toluene, used as the anti-solvent, was dripped dynamically onto the underlying spinning substrate, for the last $5 \mathrm{~s}$ of the second stage ramp to $5100 \mathrm{rpm}$. The stack was then thermally treated at $125^{\circ} \mathrm{C}$ for $20 \mathrm{~min}$. For the hole transport layer (HTL), the spiro-OMeTAD $\left(86 \mathrm{mg} \mathrm{mL}^{-1}\right.$ in chlorobenzene) was doped with three solutions, all used in conjunction, consisting of $34 \mu \mathrm{L}$ of TBP, $20 \mu \mathrm{L}$ of Li-TFSI and $11 \mu \mathrm{L}$ FK209. For the latter two solutions, i.e., Li-TFSI, a mother solution of $500 \mathrm{mg} / \mathrm{mL}$ in acetonitrile was used, while the FK209 required a mother solution of $300 \mathrm{mg} / \mathrm{mL}$ in acetonitrile. This spiro-OMeTAD solution was spin coated onto the underlying perovskite layer at $4000 \mathrm{rpm}$ for $20 \mathrm{~s}$ to form the HTL in our PSC. Finally, an $\sim 80 \mathrm{~nm}$ thick Au top electrode was deposited using e-beam evaporation at a pressure of $\sim 10^{-5}$ Torr.

\subsection{PSC Device Characterization}

The electrical characteristics of our fabricated PSCs were measured under one-sun optical illumination, i.e., $100 \mathrm{~mW} \mathrm{~cm}^{-2}$, using the Oriel LSH-7320 LED solar simulator connected to a source meter unit from Ossila (Model: X200). The light was calibrated with a standard mono-Si solar cell (PVM-396, PV Measurements Inc., Boulder, CO, USA) certified by the US National Renewable Energy Laboratory (NREL).

\section{Results and Discussion}

Various perovskite films with an equimolar ratio of $\mathrm{MAI}: \mathrm{PbI}_{2}$, i.e., (1.0:1.0), (1.2:1.2), (1.5:1.5), and (1.6:1.6), were synthesized as described in the device fabrication section and characterized using SEM, XRD, UV-vis, and PL. First, the morphological characteristics of the perovskite films prepared on the glass substrates were examined via SEM, as shown in 
Figure 2a-d. The SEM image of (1:1) film formulation shows that the perovskite crystallization process did not reach completion, given the very small size of the grains buried in the midst of cracked islands comprised of a significant density of pinholes. Similarly, the (1.2:1.2) and (1.6:1.6) formulations showed improper perovskite crystallization, again with a high density of cracks and pinholes. However, the (1.5:1.5) film appears to be much better than the rest of the films due to a denser morphology with a far lower density of visible pinholes and cracks for this composition.
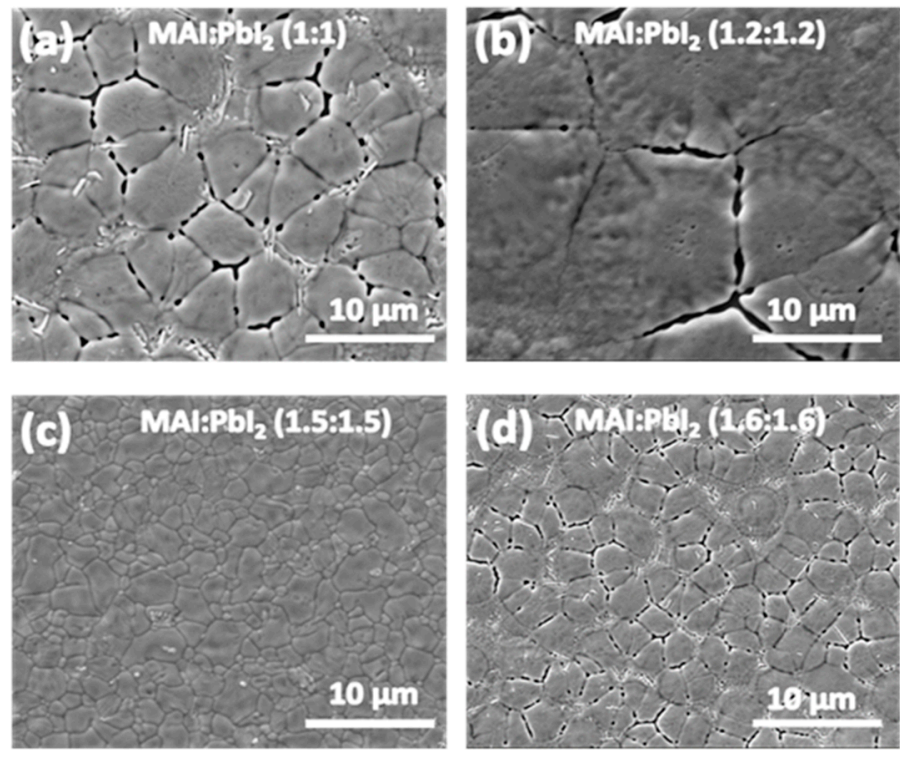

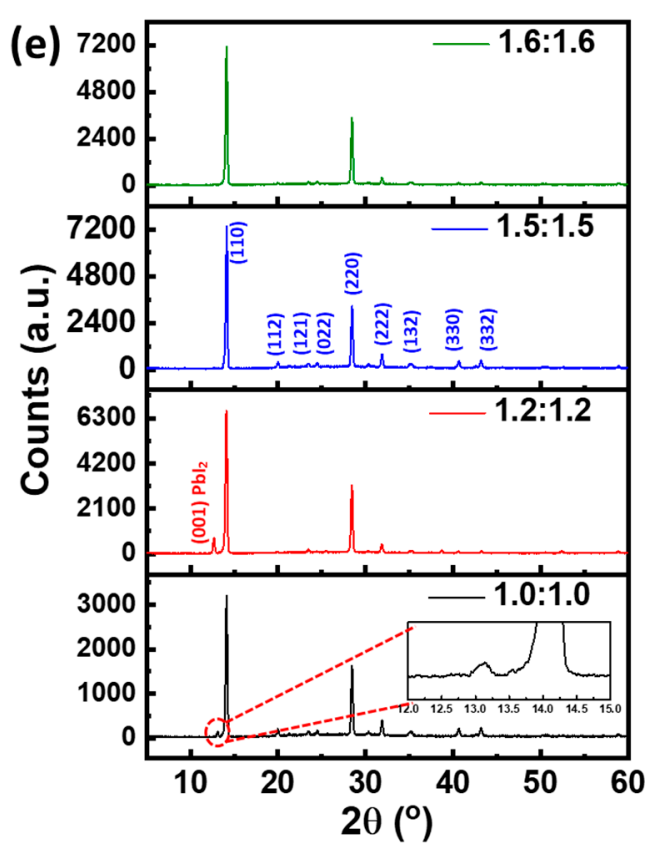

Figure 2. The SEM images of the perovskite films fabricated on glass substrates using different equimolar concentrations of MAI:PbI 2 : (a) (1.0:1.0), (b) (1.2:1.2), (c) (1.5:1.5), and (d) (1.6:1.6). (e) XRD spectra of the perovskite films synthesized on glass substrates at the increasing equimolar ratios of $\mathrm{MAI}: \mathrm{PbI}_{2}$ from bottom-to-top. Inset in the bottom panel shows the magnified region in XRD spectra for (1.0:1.0) film at $13.14^{\circ}$ ascribed to the $\mathrm{PbI}_{2}$ peak.

Shown in Figure 2e are the XRD spectra of the fabricated absorber layers at these four compositions, and the results are in good agreement with prior reports [38]. The (1.5:1.5) film shows relatively intense peaks for the (110), (112), (121), (020), (220), and (222) planes with their intensity counts being higher than the other films, suggesting the better crystallinity of the (1.5:1.5) film, as compared to the rest of the samples; this in alignment with the SEM data taken for the (1.5:1.5) composition, where a compact morphology is evident (Figure 2c). While the presence of the $\mathrm{PbI}_{2}$ impurity peak for the (1.0:1.0) and (1.2:1.2) formulations located at $\sim 12.5-13^{\circ}$ is not ideal, this peak could also arise from the onset of post-synthesis degradation upon exposure to ambient conditions [39], or possible instrumentation resolution errors in measuring minute microgram resolution of precursor masses. Additionally, the magnified image of the XRD spectra for the (1:1) formulation at $13.14^{\circ}$ is shown in the inset of Figure 2e, bottom panel. The crystallite size as it pertains to the (110) peak was calculated using the Scherrer relation, $S=\frac{K \lambda}{\beta \cos \theta}$, where $S$ is the estimated crystallite grain size, $\lambda=0.15406 \AA$ for the wavelength of the $X$-rays used in the diffractometer, $\beta$ represents the full-width-half-maximum (FWHM) in radians, $\theta$ is the diffraction Bragg angle, $K$ is the Scherrer constant, which was taken to be $\sim 0.94$, as characteristic of spherical crystals with cubic symmetry, which we assumed likely for our samples [40]. Based on the above analysis, the crystallite size for the films was calculated to be $43.4 \mathrm{~nm}(1.0: 1.0)<44.2 \mathrm{~nm}(1.2: 1.2)<45.5 \mathrm{~nm}(1.6: 1.6)<48.1 \mathrm{~nm}(1.5: 1.5)$, as summarized in Table 1. Even though the variation between the sizes is very small based on this calculation, the data are consistent with the crystallite size being largest for the (1.5:1.5) film compared to the other films. 
Table 1. Crystallite grain size of perovskite films for all four formulations.

\begin{tabular}{cccc}
\hline $\begin{array}{c}\mathbf{M A P b I}_{\mathbf{3}} \\
\left(\mathbf{M A I}_{\mathbf{P b I}} \mathbf{)}\right.\end{array}$ & Peak Position $(\boldsymbol{\theta})$ & $\begin{array}{c}\text { FWHM } \\
\text { (Radian) }\end{array}$ & Crystallite Size (nm) \\
\hline $1.0: 1.0$ & 7.06 & 0.00337 & 43.4 \\
\hline $1.2: 1.2$ & 7.05 & 0.00330 & 44.2 \\
\hline $1.5: 1.5$ & 7.06 & 0.00303 & 48.1 \\
\hline $1.6: 1.6$ & 7.06 & 0.00321 & 45.5 \\
\hline
\end{tabular}

The thickness profile of the films is shown in Figure 3, measured using atomic force microscopy (AFM). The nominal film thickness $h$ for the (1.0:1.0), (1.2:1.2), (1.5:1.5), and (1.6:1.6) formulations was measured to be $287 \pm 97 \mathrm{~nm}<317 \pm 72 \mathrm{~nm}<337 \pm 58 \mathrm{~nm}<346 \pm 66 \mathrm{~nm}$, respectively. The uncertainty values associated with each thickness (formulation) represent the average roughness $\left(R_{\text {avg }}\right)$ acquired from the AFM, and a slight trending toward increasing nominal thickness was observed as the molar ratio was increased, despite the wide variability in $R_{a v g}$, not uncommon for spin-coated perovskite films. The slight increase in the average thickness with increasing concentration may be linked to the associated increase in viscosity since the spin coating parameters remained fixed.

(a)
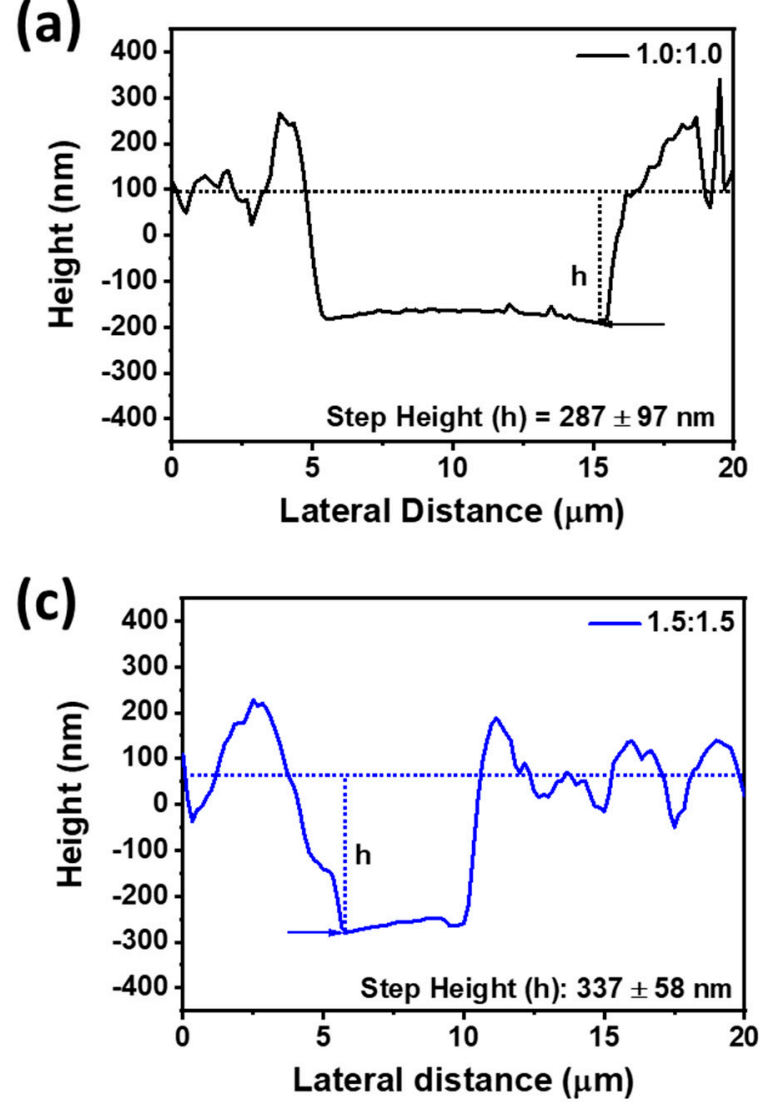

(b)

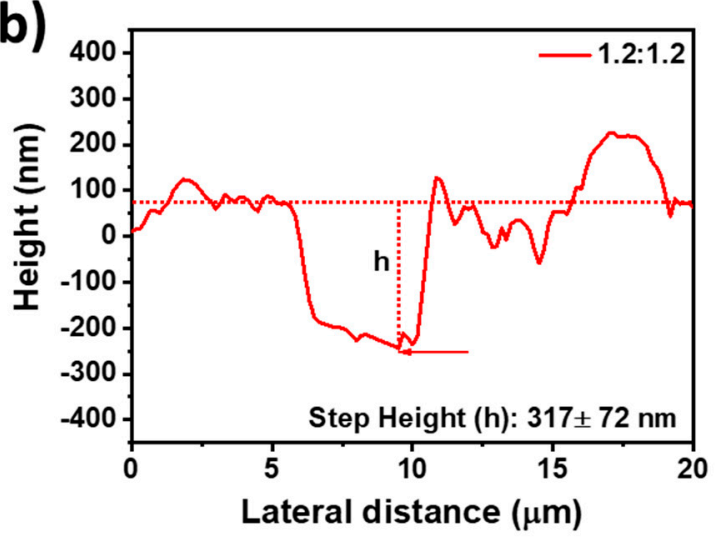

(d)

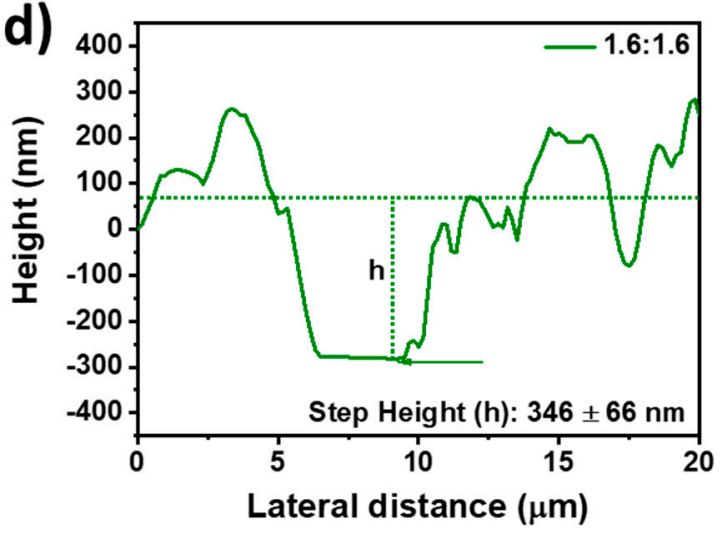

Figure 3. Perovskite films on glass substrates with film thickness $h$ obtained from AFM for the various equimolar concentrations of MAI:PbI ${ }_{2}$ with $R_{a v g}$ as uncertainty values for, (a) (1.0:1.0): $287 \pm 97 \mathrm{~nm}$, (b) (1.2:1.2): $317 \pm 72 \mathrm{~nm}$, (c) (1.5:1.5): $337 \pm 58 \mathrm{~nm}$, and (d) (1.6:1.6): $346 \pm 66 \mathrm{~nm}$.

The UV-vis optical absorption profiles for all the fabricated films are shown in Figure 4a. For comparison, the absorption profiles of all the $\mathrm{MAPbI}_{3}$ perovskite films were in agreement with the prior reported studies [41]. Here, it can be seen that the (1.5:1.5) film showed optimal absorption characteristics amongst all the films, which is consistent with its compact morphology, as corroborated through the SEM imaging re- 
sults in Figure 2c. A validation of the slight increase in thickness with an increase in concentration is also evident in the absorption data, where the absorbance increased as the concentration increased, i.e., from the smallest concentration (1.0:1.0) to the highest concentrations, specifically (1.5:1.5) and (1.6:1.6). The absorbance of the (1.5:1.5) and (1.6:1.6) films was almost identical up until about $575 \mathrm{~nm}$, and below $550 \mathrm{~nm}$, the absorbance of the (1.5:1.5) film increased at these shorter wavelengths. This is likely due to the fact that the (1.5:1.5) film depicts a more compact morphology with fewer pinholes compared to all the other film formulations, which may contribute to its slight enhancement in absorbance when compared to the almost equally thick (1.6:1.6) film. The PL emission peak (Figure $4 \mathrm{~b}$ ), for all the fabricated perovskite samples, lies in the vicinity of $\sim 778 \mathrm{~nm}$ and aligns well with the prior literature for $\mathrm{MAPbI}_{3}$ films [42]. The lesser PL counts or highest PL quenching for the (1.5:1.5) perovskite formulation on c- $\mathrm{TiO}_{2} / \mathrm{FTO} /$ glass substrates may be likely due to the more efficient charge extraction between the $\mathrm{c}-\mathrm{TiO}_{2}$ and perovskite layer, which further suggests that the (1.5:1.5) film is more suitable for the PSC devices. However, since PL quenching can also arise from non-radiative recombination, steady-state PL, when combined with time-resolved photoluminescence (TRPL), would provide a firmer validation of the efficiency of the charge carrier extraction process, which will be conducted in a future study.

(a)

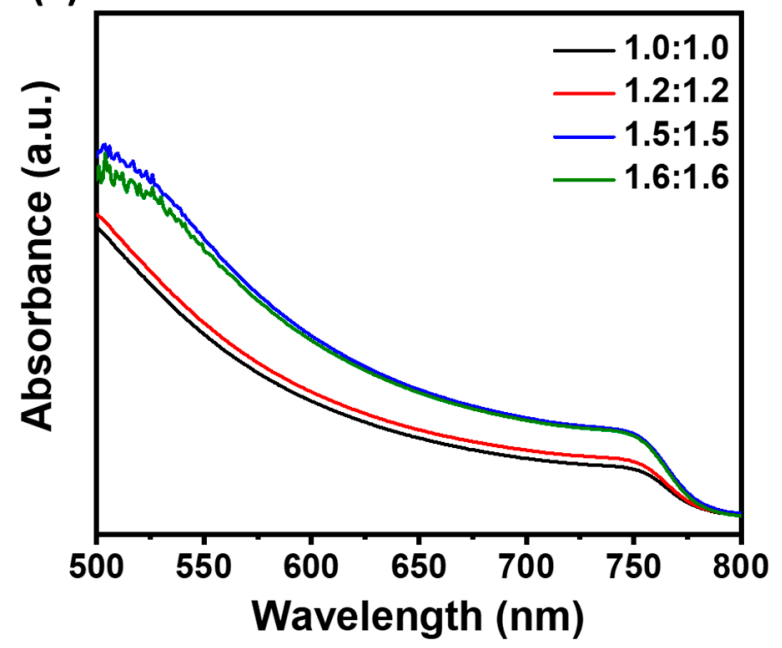

(b)

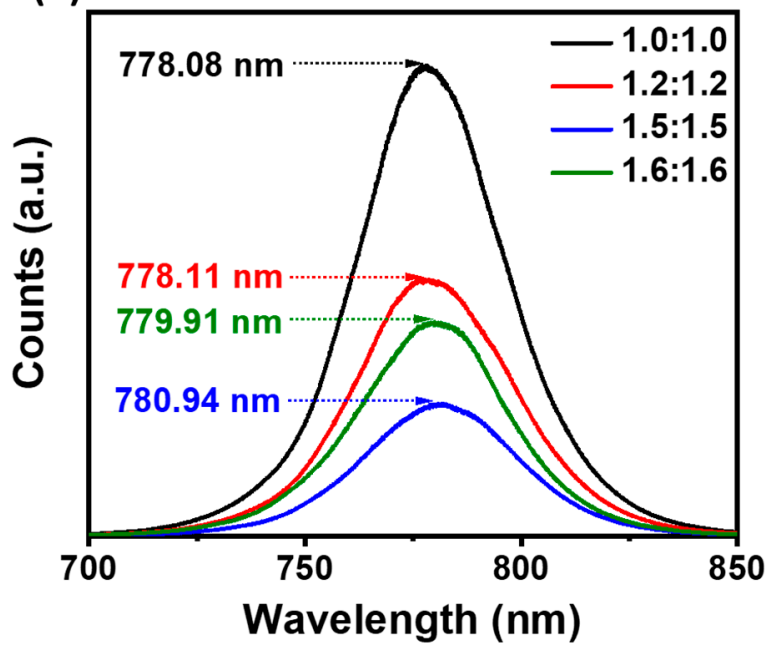

Figure 4. (a) The UV-vis spectra gathered for $\mathrm{MAPbI}_{3}$ perovskite films synthesized on $\mathrm{c}-\mathrm{TiO}_{2} / \mathrm{FTO} /$ glass substrates. (b) The $\mathrm{PL}$ spectra of the perovskite films fabricated on $\mathrm{c}-\mathrm{TiO}_{2} / \mathrm{FTO} /$ glass substrates, showing the maximum PL quenching for the (1.5:1.5) formulation, with the peaks largely centered around $778 \mathrm{~nm}$.

PSCs with all four formulations were fabricated based on the n-i-p architecture (Au/Spiro$\mathrm{OMeTAD} / \mathrm{MAPbI}_{3} / \mathrm{c}-\mathrm{TiO}_{2} / \mathrm{FTO}$ ), as shown by the device schematic in Figure $5 \mathrm{a}$, and their recorded current density versus voltage $(J-V)$ characteristics are shown in Figure $5 \mathrm{~b}$. The (1.5:1.5) PSC exhibited a maximum PCE of $14.56 \%$ among all formulations along with an opencircuit voltage $V_{\mathrm{OC}}$ of $\sim 1.05 \mathrm{~V}$, short-circuit current density $J_{\mathrm{SC}}$ of $\sim 22.21 \mathrm{~mA} \mathrm{~cm}^{-2}$, fill-factor (FF) of $\sim 62.58 \%$, series resistance $R_{S}$ of $\sim 8.82 \Omega \mathrm{cm}^{2}$, and shunt resistance $R_{\mathrm{Sh}}$ of $\sim 3.49 \mathrm{k} \Omega \mathrm{cm}^{2}$. On the other hand, for the (1.6:1.6), (1.2:1.2) and (1.0:1.0) formulations, PCE values of $\sim 12.25 \%$, $10.98 \%$, and $9.32 \%$ were measured, respectively. The photovoltaic parameters for all PSCs are summarized in Table 2. While there is scope to improve these parameters further, the PCE trend: $(1.5: 1.5)>(1.6: 1.6)>(1.2: 1.2)>(1.0: 1.0)$, lies in good agreement with the absorption and PL spectra.

The recombination losses for the fabricated PSCs were examined by recording the light intensity-dependent $J-V$ Characteristics. Typically, the $J_{\mathrm{SC}}$ of the devices follows a power-law relationship with the incident light intensity $I$ such that, $J_{\mathrm{SC}} \propto I^{\alpha}$, where $\alpha$ is extracted from the slope of the log-log $J_{S C}$ versus I plot, as shown in Figure 6a, and it represents the extent of bimolecular recombination $[43,44]$. Usually, $\alpha$ close to unity indicates 
the presence of weak bimolecular recombination. The $\alpha$ value for the PSCs were extracted as follows: $\alpha=0.965(1.5: 1.5)>0.950(1.6: 1.6)>0.917(1.2: 1.2)>0.910(1.0: 1.0)$. Thus, these data indicate the presence of minimal bimolecular recombination in the (1.5:1.5) PSC. Meanwhile, information about the trap-assisted recombination losses can be obtained from the dependence of the $V_{\mathrm{OC}}$ and $I$, according to the following relation, where $V_{\mathrm{OC}} \propto \frac{n k T}{q} \ln (I)$. Here, $n$ is a coefficient, $k$ is the Boltzmann constant, $T$ is the temperature in Kelvin, and $q$ is the elementary charge. The value of the coefficient $n$ usually ranges between 1 and 2 , where an $n \sim 1$ indicates the absence of trap-assisted recombination, while $n>1$ suggests the presence of trap-assisted recombination [12,45]. From the fit in Figure 6b, the value of $n$ in the devices was deduced to be: $n=1.57(1.5: 1.5)<1.63(1.6: 1.6)<1.78(1.2: 1.2)<1.87(1.0: 1.0)$, which indicates that the (1.5:1.5) PSC has the least presence of trap-assisted recombination. Overall, both studies shown in Figure 6a,b suggest minimal bimolecular and trap-assisted recombination occurring in the (1.5:1.5) PSC, which also corroborates its higher PCE performance amongst all four formulations.
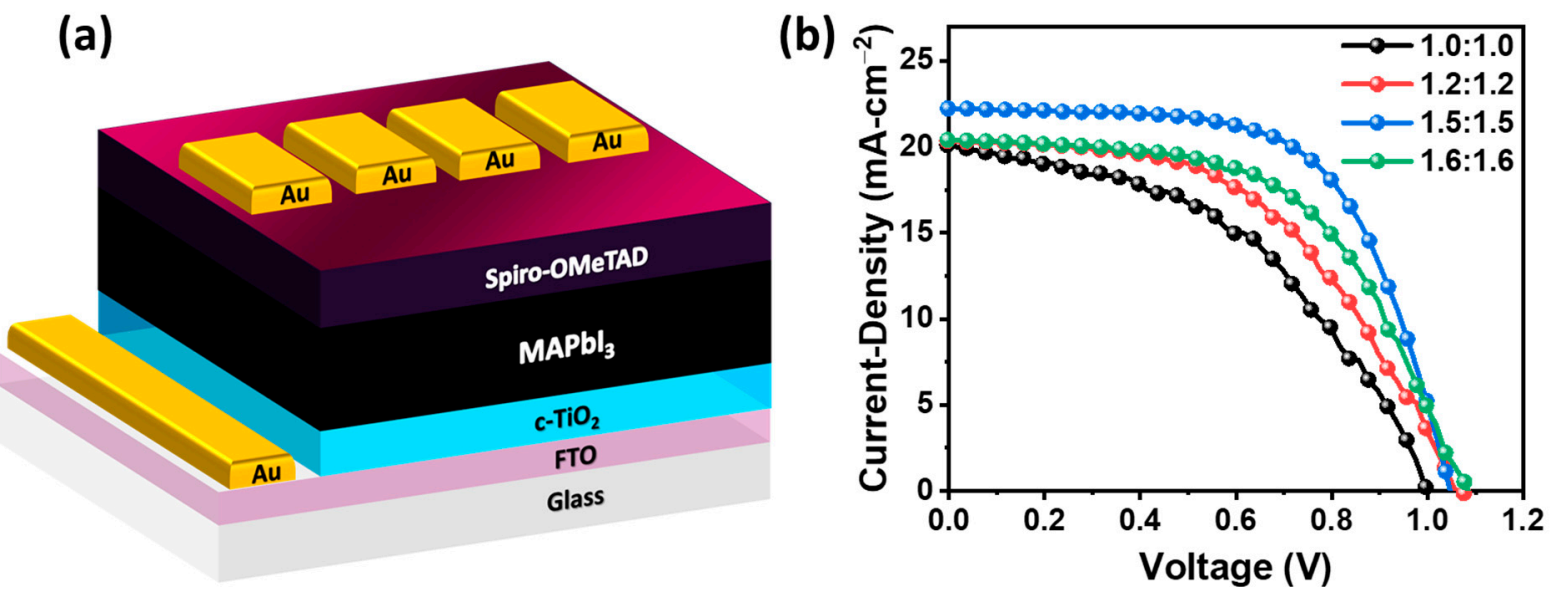

Figure 5. Device architecture of the (a) n-i-p PSCs (Au/Spiro-OMeTAD/MAPbI $3 / \mathrm{c}-\mathrm{TiO}_{2} / \mathrm{FTO} /$ glass) and (b) the $J-V$ Characteristics of the fabricated PSCs using all four formulations.

Table 2. Photovoltaic parameters of the fabricated n-i-p PSC devices.

\begin{tabular}{ccccccc}
\hline $\begin{array}{c}\mathbf{M A P b I}_{\mathbf{3}} \\
\left(\mathbf{M A I}: \mathbf{P b I}_{\mathbf{2}}\right)\end{array}$ & $\begin{array}{c}\boldsymbol{P C E} \\
\mathbf{( \% )}\end{array}$ & $\begin{array}{c}\boldsymbol{F F} \\
\mathbf{( \% )}\end{array}$ & $\begin{array}{c}J_{\mathbf{S C}} \\
\left(\mathbf{m A} \cdot \mathbf{c m}^{-2}\right)\end{array}$ & $\begin{array}{c}V_{\mathrm{OC}} \\
(\mathbf{V})\end{array}$ & $\begin{array}{c}\boldsymbol{R}_{\mathbf{S h}} \\
\left(\mathbf{k} \boldsymbol{\Omega}-\mathbf{c m}^{\mathbf{2}}\right)\end{array}$ & $\begin{array}{c}\boldsymbol{R}_{\mathbf{S}} \\
\left(\boldsymbol{\Omega}-\mathbf{c m}^{\mathbf{2}}\right)\end{array}$ \\
\hline $1.0: 1.0$ & 9.32 & 46.38 & 20.06 & 1.00 & 0.22 & 15.58 \\
\hline $1.2: 1.2$ & 10.98 & 50.75 & 20.34 & 1.06 & 1.36 & 19.33 \\
\hline $1.5: 1.5$ & 14.56 & 62.58 & 22.21 & 1.05 & 3.49 & 8.82 \\
\hline $1.6: 1.6$ & 12.25 & 55.50 & 20.39 & 1.08 & 1.29 & 16.29 \\
\hline
\end{tabular}

Moreover, the continuous evolution of photovoltaic parameters for (1.5:1.5) PSC with time up to $10 \mathrm{~h}$ were monitored while keeping the device at its maximum power point, as shown by the data in Figure $7 \mathrm{~b}$. The relative humidity $(\mathrm{RH})$ and ambient temperature during the experiment were noted to be $\sim 60 \%$ and $\sim 29^{\circ} \mathrm{C}$, respectively. It can be seen that the (1.5:1.5) PSC retained $\sim 90 \%$ of its initial $V_{\mathrm{OC}}$ and $F F$ after $10 \mathrm{~h}$ of continuous tracking, but the $J_{\mathrm{SC}}$ and PCE decreased to $\sim 70 \%$ and $\sim 60 \%$, respectively, of their initial values for the same duration. There might be a number of possible reasons for the $J_{\mathrm{SC}}$ loss attributed to photo-oxidization, or degradation of the charge extraction layers, or their degraded interfaces with the perovskite reducing the charge extraction efficiency [46,47], which will be examined further in future work. 
(a)

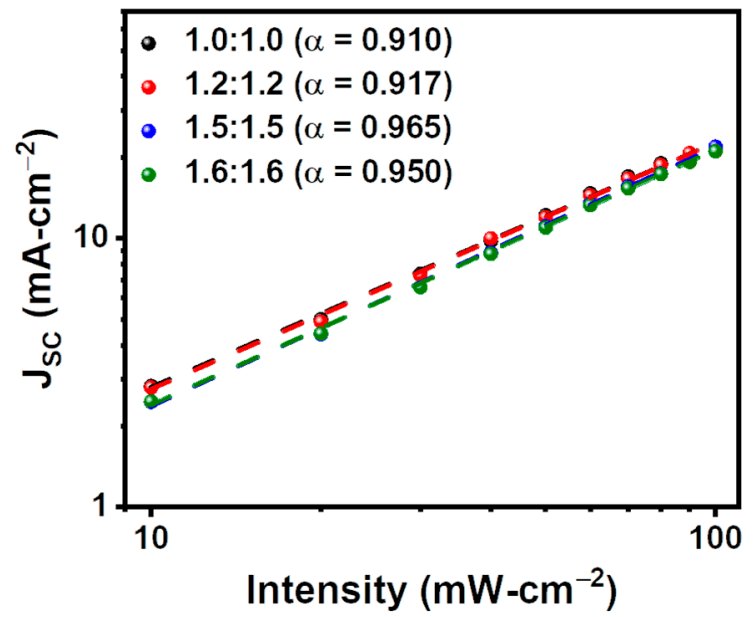

(b)

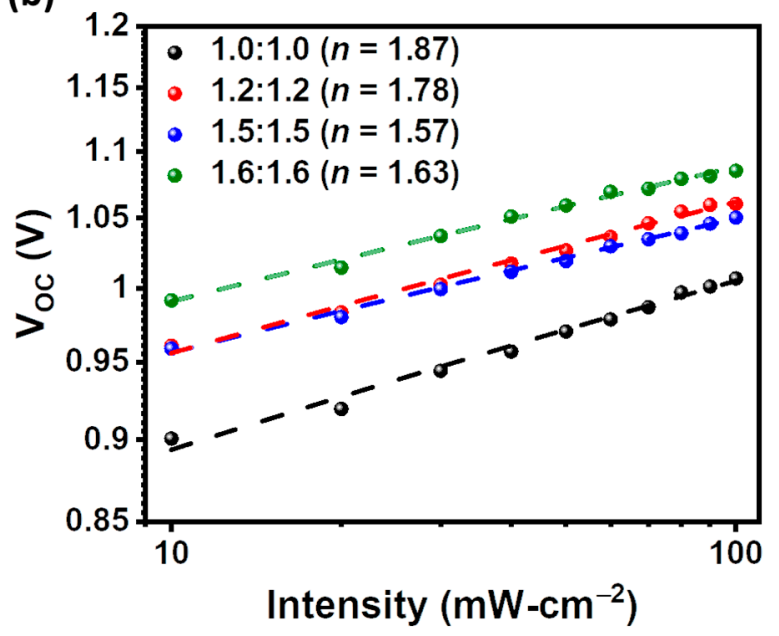

Figure 6. The light intensity-dependent $J-V$ Characteristics of the n-i-p PSCs: (a) $J_{\mathrm{SC}}$ versus light intensity, and (b) $V_{\mathrm{OC}}$ versus light intensity, where the light intensity was varied from 0.1 sun to 1 sun.

(a)

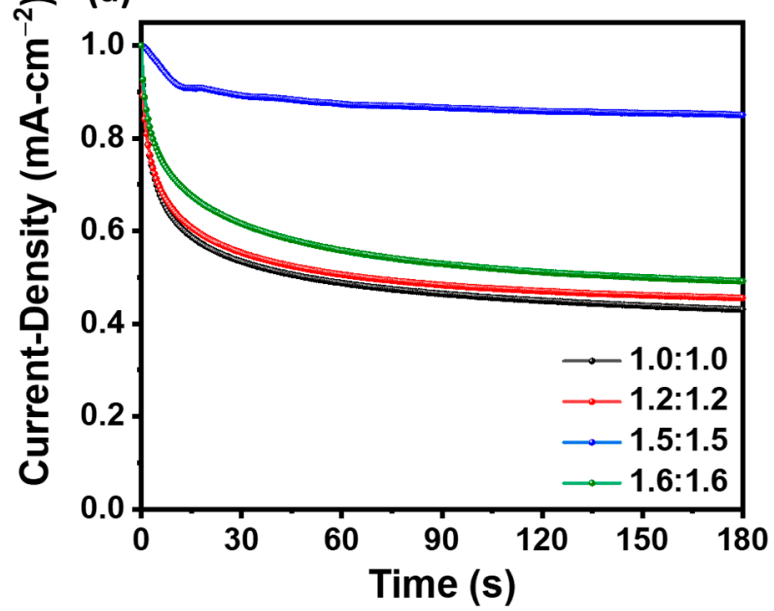

(b)

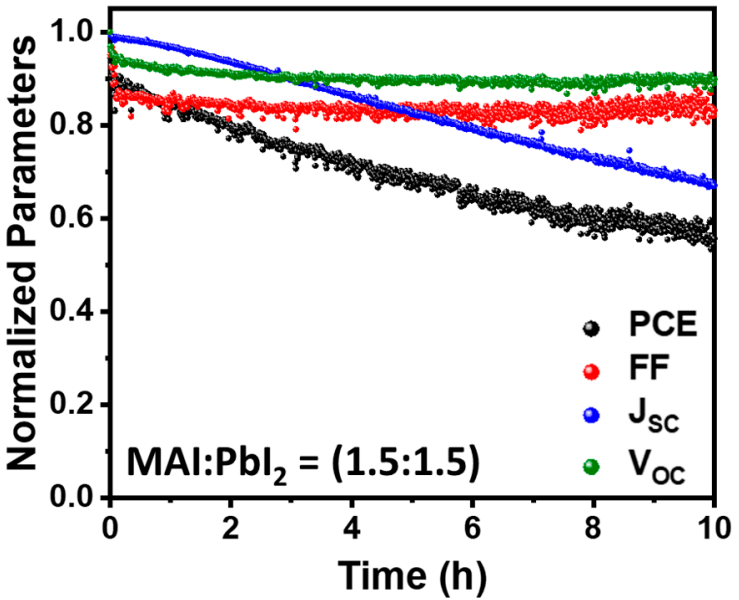

Figure 7. (a) The stabilized current output of PSC devices at $0.6 \mathrm{~V}$ for $3 \mathrm{~min}$, and (b) the evolution of PV parameters with respect to time when the (1.5:1.5) PSC device was held at its maximum power point.

\section{Conclusions}

In summary, perovskite films with various equimolar concentrations of $\mathrm{MAI}$ and $\mathrm{PbI}_{2}$ were synthesized and analyzed. The (1.0:1.0), (1.2:1.2), and (1.6:1.6) films did not appear to be optimal and exhibited pinholes and cracks within the photoabsorber, and thus these films were not suitable for the PV device fabrication of the solar cell stack. However, the (1.5:1.5) formulation exhibited a compact morphology which appeared more suitable as a photoabsorber in the PSCs. Accordingly, PSCs fabricated using the (1.5:1.5) films exhibited a PCE of $\sim 14.56 \%$ for the n-i-p structure. Operational stability analysis was conducted, and the continuous evolution of photovoltaic parameters with time up to $10 \mathrm{~h}$ was monitored while keeping the device at its maximum power point, which revealed that the $(1.5: 1.5)$ PSC retained $\sim 90 \%$ of its initial $V_{\text {OC }}$ and FF after $10 \mathrm{~h}$ of continuous tracking, but the $J_{\text {SC }}$ and PCE decreased to $\sim 70 \%$ and $\sim 60 \%$, respectively, of their initial values during the same amount of time. These results provide a benchmark to further tune the materials synthesis and device fabrication efforts to form higher performance PSCs in the future. 
Author Contributions: Conceptualization, A.B.K. and M.P.; Experimental Methodology, M.P.; Results Analysis and Discussion, M.P. and A.B.K.; writing-original draft preparation, M.P.; writing-review and editing, A.B.K. and M.P.; supervision, A.B.K.; project administration, A.B.K.; funding acquisition, A.B.K. All authors have read and agreed to the published version of the manuscript.

Funding: This research was funded by the Office of Naval Research (ONR) (Grant No. N00014-20-12597) and the PACCAR Technology Institute at the University of North Texas.

Institutional Review Board Statement: Not Applicable.

Informed Consent Statement: Not Applicable.

Data Availability Statement: The data presented in this study are available on request from the corresponding author.

Acknowledgments: We are grateful to Mohin Sharma from UNT for technical assistance and useful discussions. We thank the Office of Naval Research (grant number ONR N00014-20-1-2597) that enabled us to pursue this work. A.B.K. is also grateful for the support from the PACCAR Technology Institute at UNT and the Endowed Professorship.

Conflicts of Interest: The authors declare no conflict of interest.

\section{References}

1. Novoselov, K.S.; Geim, A.K.; Morozov, S.V.; Jiang, D.; Zhang, Y.; Dubonos, S.V.; Grigorieva, I.V.; Firsov, A.A. Electric Field in Atomically Thin Carbon Films. Science 2004, 306, 666-669. [CrossRef] [PubMed]

2. Jayaramulu, K.; Horn, M.; Schneemann, A.; Saini, H.; Bakandritsos, A.; Ranc, V.; Petr, M.; Stavila, V.; Narayana, C.; Scheibe, B.; et al. Covalent Graphene-MOF Hybrids for High-Performance Asymmetric Supercapacitors. Adv. Mater. 2021, 33, 202004560. [CrossRef] [PubMed]

3. Min, M.; Sakri, S.; Saenz, G.A.; Kaul, A.B. Photophysical Dynamics in Semiconducting Graphene Quantum Dots Integrated with 2D MoS2 for Optical Enhancement in the near UV. ACS Appl. Mater. Interfaces 2021, 13, 5379-5389. [CrossRef]

4. Mehta, R.K.; Kaul, A.B. Black Phosphorus-Molybdenum Disulfide Hetero-Junctions Formed with Ink-Jet Printing for Potential Solar Cell Applications with Indium-Tin-Oxide. Crystals 2021, 11, 560. [CrossRef]

5. Park, N.G. Perovskite Solar Cells: An Emerging Photovoltaic Technology. Mater. Today 2015, 18, 65-72. [CrossRef]

6. $\quad$ Lin, K.; Xing, J.; Quan, L.N.; de Arquer, F.P.G.; Gong, X.; Lu, J.; Xie, L.; Zhao, W.; Zhang, D.; Yan, C.; et al. Perovskite Light-Emitting Diodes with External Quantum Efficiency Exceeding 20 per Cent. Nature 2018, 562, 245-248. [CrossRef] [PubMed]

7. Liu, P.; He, X.; Ren, J.; Liao, Q.; Yao, J.; Fu, H. Organic-Inorganic Hybrid Perovskite Nanowire Laser Arrays. ACS Nano 2017, 11, 5766-5773. [CrossRef]

8. Yang, Y.; Dai, H.; Yang, F.; Zhang, Y.; Luo, D.; Zhang, X.; Wang, K.; Sun, X.W.; Yao, J. All-Perovskite Photodetector with Fast Response. Nanoscale Res. Lett. 2019, 14, 291. [CrossRef]

9. Hossain, R.F.; Min, M.; Ma, L.C.; Sakri, S.R.; Kaul, A.B. Carrier Photodynamics in 2D Perovskites with Solution-Processed Silver and Graphene Contacts for Bendable Optoelectronics. npj 2D Mater. Appl. 2021, 5, 34. [CrossRef]

10. Min, M.; Hossain, R.F.; Adhikari, N.; Kaul, A.B. Inkjet-Printed Organohalide 2D Layered Perovskites for High-Speed Photodetectors on Flexible Polyimide Substrates. ACS Appl. Mater. Interfaces 2020, 12, 10809-10819. [CrossRef] [PubMed]

11. Huang, H.; Pradhan, B.; Hofkens, J.; Roeffaers, M.B.J.; Steele, J.A. Solar-Driven Metal Halide Perovskite Photocatalysis: Design, Stability, and Performance. ACS Energy Lett. 2020, 5, 1107-1123. [CrossRef]

12. Singh, R.; Parashar, M.; Sandhu, S.; Yoo, K.; Lee, J.J. The Effects of Crystal Structure on the Photovoltaic Performance of Perovskite Solar Cells under Ambient Indoor Illumination. Sol. Energy 2021, 220, 43-50. [CrossRef]

13. Parashar, M.; Singh, R.; Shukla, V.K. Fabrication of Perovskite Solar Cells in Ambient Conditions. Mater. Today Proc. 2019, 34, 654-657. [CrossRef]

14. Stranks, S.D.; Eperon, G.E.; Grancini, G.; Menelaou, C.; Alcocer, M.J.P.; Leijtens, T.; Herz, L.M.; Petrozza, A.; Snaith, H.J. ElectronHole Diffusion Lengths Exceeding 1 Micrometer in an Organometal Trihalide Perovskite Absorber. Science 2013, 342, $341-344$. [CrossRef]

15. Dong, Q.; Fang, Y.; Shao, Y.; Mulligan, P.; Qiu, J.; Cao, L.; Huang, J. Electron-Hole Diffusion Lengths > 175 Mm in Solution-Grown CH3NH3PbI3 Single Crystals. Science 2015, 347, 967-970. [CrossRef] [PubMed]

16. Savenije, T.J.; Ponseca, C.S.; Kunneman, L.; Abdellah, M.; Zheng, K.; Tian, Y.; Zhu, Q.; Canton, S.E.; Scheblykin, I.G.; Pullerits, T.; et al. Thermally Activated Exciton Dissociation and Recombination Control the Carrier Dynamics in Organometal Halide Perovskite. J. Phys. Chem. Lett. 2014, 5, 2189-2194. [CrossRef]

17. Wetzelaer, G.J.A.H.; Scheepers, M.; Sempere, A.M.; Momblona, C.; Ávila, J.; Bolink, H.J. Trap-Assisted Non-Radiative Recombination in Organic-Inorganic Perovskite Solar Cells. Adv. Mater. 2015, 27, 1837-1841. [CrossRef] [PubMed]

18. Nazeeruddin, M.K.; Snaith, H. Methylammonium Lead Triiodide Perovskite Solar Cells: A New Paradigm in Photovoltaics. MRS Bull. 2015, 40, 641-645. [CrossRef] 
19. Liang, H.; Yuan, F.; Johnston, A.; Gao, C.; Choubisa, H.; Gao, Y.; Wang, Y.K.; Sagar, L.K.; Sun, B.; Li, P.; et al. High Color Purity Lead-Free Perovskite Light-Emitting Diodes via Sn Stabilization. Adv. Sci. 2020, 7, 1903213. [CrossRef]

20. Younis, A.; Lin, C.H.; Guan, X.; Shahrokhi, S.; Huang, C.Y.; Wang, Y.; He, T.; Singh, S.; Hu, L.; Retamal, J.R.D.; et al. Halide Perovskites: A New Era of Solution-Processed Electronics. Adv. Mater. 2021, 33, 2005000. [CrossRef] [PubMed]

21. Goldschmidt, V.M. Krystallbau Und Chemische Zusammensetzung. Ber. Dtsch. Chem. Ges. 1927, 60, 1263-1296. [CrossRef]

22. Li, C.; Lu, X.; Ding, W.; Feng, L.; Gao, Y.; Guo, Z. Formability of ABX 3 (X = F, Cl, Br, I) Halide Perovskites. Acta Crystallogr. Sect. B Struct. Sci. 2008, 64, 702-707. [CrossRef]

23. Stevenson, J.; Sorenson, B.; Subramaniam, V.H.; Raiford, J.; Khlyabich, P.P.; Loo, Y.L.; Clancy, P. Mayer Bond Order as a Metric of Complexation Effectiveness in Lead Halide Perovskite Solutions. Chem. Mater. 2017, 29, 2435-2444. [CrossRef]

24. Hoang, M.T.; Ünlü, F.; Martens, W.; Bell, J.; Mathur, S.; Wang, H. Towards the Environmentally Friendly Solution Processing of Metal Halide Perovskite Technology. Green Chem. 2021, 23, 5302-5336. [CrossRef]

25. Lee, J.W.; Park, N.G. Two-Step Deposition Method for High-Efficiency Perovskite Solar Cells. MRS Bull. 2015, 40, 654-659. [CrossRef]

26. An, Q.; Sun, Q.; Weu, A.; Becker-Koch, D.; Paulus, F.; Arndt, S.; Stuck, F.; Hashmi, A.S.K.; Tessler, N.; Vaynzof, Y. Enhancing the Open-Circuit Voltage of Perovskite Solar Cells by up to 120 MV Using П-Extended Phosphoniumfluorene Electrolytes as Hole Blocking Layers. Adv. Energy Mater. 2019, 9, 1901257. [CrossRef]

27. Liu, C.; Yang, Y.; Syzgantseva, O.A.; Ding, Y.; Syzgantseva, M.A.; Zhang, X.; Asiri, A.M.; Dai, S.; Nazeeruddin, M.K. $\alpha$-CsPbI3 Bilayers via One-Step Deposition for Efficient and Stable All-Inorganic Perovskite Solar Cells. Adv. Mater. 2020, $32,2002632$. [CrossRef]

28. Jung, M.; Ji, S.G.; Kim, G.; Seok, S.I. Perovskite Precursor Solution Chemistry: From Fundamentals to Photovoltaic Applications. Chem. Soc. Rev. 2019, 48, 2011-2038. [CrossRef]

29. Burschka, J.; Pellet, N.; Moon, S.J.; Humphry-Baker, R.; Gao, P.; Nazeeruddin, M.K.; Grätzel, M. Sequential Deposition as a Route to High-Performance Perovskite-Sensitized Solar Cells. Nature 2013, 499, 316-319. [CrossRef] [PubMed]

30. Cohen, B.-E.; Gamliel, S.; Etgar, L. Parameters Influencing the Deposition of Methylammonium Lead Halide Iodide in Hole Conductor Free Perovskite-Based Solar Cells. APL Mater. 2014, 2, 081502. [CrossRef]

31. Im, J.; Jang, I.-H.; Norman, P.; Michael, G.; Park, N.-G. Growth of CH3NH3PbI3 Cuboids with Controlled Size for High-Efficiency Perovskite Solar Cells. Nat. Nanotechnol. 2014, 9, 927-932. [CrossRef]

32. Im, J.H.; Kim, H.S.; Park, N.G. Morphology-Photovoltaic Property Correlation in Perovskite Solar Cells: One-Step versus Two-Step Deposition of $\mathrm{CH}_{3} \mathrm{NH}_{3} \mathrm{PbI}_{3}$. APL Mater. 2014, 2, 081510. [CrossRef]

33. Jeon, N.J.; Noh, J.H.; Kim, Y.C.; Yang, W.S.; Ryu, S.; Seok, S.I. Solvent Engineering for High-Performance Inorganic-Organic Hybrid Perovskite Solar Cells. Nat. Mater. 2014, 13, 897-903. [CrossRef] [PubMed]

34. Tavakoli, M.M.; Yadav, P.; Prochowicz, D.; Sponseller, M.; Osherov, A.; Bulović, V.; Kong, J. Controllable Perovskite Crystallization via Antisolvent Technique Using Chloride Additives for Highly Efficient Planar Perovskite Solar Cells. Adv. Energy Mater. 2019, 9, 1803587. [CrossRef]

35. Lee, J.W.; Kim, H.S.; Park, N.G. Lewis Acid-Base Adduct Approach for High Efficiency Perovskite Solar Cells. Acc. Chem. Res. 2016, 49, 311-319. [CrossRef]

36. Taylor, A.D.; Sun, Q.; Goetz, K.P.; An, Q.; Schramm, T.; Hofstetter, Y.; Litterst, M.; Paulus, F.; Vaynzof, Y. A General Approach to High-Efficiency Perovskite Solar Cells by Any Antisolvent. Nat. Commun. 2021, 12, 1878. [CrossRef] [PubMed]

37. Liu, S.; Guan, Y.; Sheng, Y.; Hu, Y.; Rong, Y.; Mei, A.; Han, H. A Review on Additives for Halide Perovskite Solar Cells. Adv. Energy Mater. 2020, 10, 1902492. [CrossRef]

38. Chen, Z.; Turedi, B.; Alsalloum, A.Y.; Yang, C.; Zheng, X.; Gereige, I.; Alsaggaf, A.; Mohammed, O.F.; Bakr, O.M. Single-Crystal MAPbI3 Perovskite Solar Cells Exceeding 21\% Power Conversion Efficiency. ACS Energy Lett. 2019, 4, 1258-1259. [CrossRef]

39. Kim, B.; Kim, M.; Lee, J.H.; Seok, S.I. Enhanced Moisture Stability by Butyldimethylsulfonium Cation in Perovskite Solar Cells. Adv. Sci. 2020, 7, 1901840. [CrossRef]

40. El-Henawey, M.I.; Gebhardt, R.S.; El-Tonsy, M.M.; Chaudhary, S. Organic solvent vapor treatment of lead iodide layers in the two-step sequential deposition of CH3NH3PbI3-based perovskite solar cells. J. Mater. Chem. A 2016, 4, 1947-1952. [CrossRef]

41. Park, N.G. High Efficiency Perovskite Solar Cells: Materials and Devices Engineering. Trans. Electr. Electron. Mater. 2020, $21,1-15$. [CrossRef]

42. Shalan, A.E.; Oshikiri, T.; Narra, S.; Elshanawany, M.M.; Ueno, K.; Wu, H.P.; Nakamura, K.; Shi, X.; Diau, E.W.G.; Misawa, H. Cobalt Oxide (CoOx) as an Efficient Hole-Extracting Layer for High-Performance Inverted Planar Perovskite Solar Cells. ACS Appl. Mater. Interfaces 2016, 8, 33592-33600. [CrossRef] [PubMed]

43. Koster, L.J.A.; Mihailetchi, V.D.; Xie, H.; Blom, P.W.M. Origin of the Light Intensity Dependence of the Short-Circuit Current of Polymer/Fullerene Solar Cells. Appl. Phys. Lett. 2005, 87, 203502. [CrossRef]

44. Sharma, A.; Singh, R.; Kini, G.P.; Hyeon Kim, J.; Parashar, M.; Kim, M.; Kumar, M.; Kim, J.S.; Lee, J.J. Side-Chain Engineering of Diketopyrrolopyrrole-Based Hole-Transport Materials to Realize High-Efficiency Perovskite Solar Cells. ACS Appl. Mater. Interfaces 2021, 13, 7405-7415. [CrossRef] [PubMed]

45. Cowan, S.R.; Roy, A.; Heeger, A.J. Recombination in Polymer-Fullerene Bulk Heterojunction Solar Cells. Phys. Rev. B-Condens. Matter Mater. Phys. 2010, 82, 245207. [CrossRef] 
46. Christians, J.A.; Schulz, P.; Tinkham, J.S.; Schloemer, T.H.; Harvey, S.P.; Tremolet De Villers, B.J.; Sellinger, A.; Berry, J.J.; Luther, J.M. Tailored Interfaces of Unencapsulated Perovskite Solar Cells for $>1000$ Hour Operational Stability. Nat. Energy 2018, 3, 68-74. [CrossRef]

47. Alsari, M.; Pearson, A.J.; Wang, J.T.W.; Wang, Z.; Montisci, A.; Greenham, N.C.; Snaith, H.J.; Lilliu, S.; Friend, R.H. Degradation Kinetics of Inverted Perovskite Solar Cells. Sci. Rep. 2018, 8, 5977. [CrossRef] [PubMed] 